\title{
ALLOCATION OF CAPITAL BETWEEN ASSETS AND LIABILITIES
}

BY

YINGJIE ZHANG

\begin{abstract}
We propose a capital allocation method for insurance companies. The amount of capital is directly related to the default risk. The expected value of default can be distributed among the liabilities based on the rule of asset payoff at the time of default. We derive a capital allocation scheme from this allocation of the expected default. Assets, liabilities, and other risky items on the balance sheet are treated in a uniform framework. The insurer's capital is allocated among all these risk contributors. The allocated capitals are given in closed-form formulas, which have straightforward interpretations and are easy to compute. Connections with other allocation methods are also discussed.
\end{abstract}

\section{KEYWORDS}

Capital allocation, expected value of default.

\section{INTRODUCTION}

Insurance companies allocate capital for at least two purposes - pricing and profit measurement. The allocated capital is the basis for calculating charges for the cost of capital, and for measuring risk adjusted profits with the ROE or similar ratios. In most practices, an allocation process begins with the selection of a risk measure, typically one of the value-at-risk (VaR), the tail value-at-risk (TVaR), or the standard deviation (SD). The risk measure is then used to calculate the required capital for members in a desired level of granularity (lines of business, underwriting units, or policies), each member treated as a standalone company. Since the members support each other, the amount of capital needed for the whole company is less than the sum of the standalone capitals. An allocation rule is then chosen for spreading the total capital among the members. Commonly used rules include the proportional spread, the marginal spread, and the Shapley algorithm. See Venter (2003) for a detailed review. These allocation schemes, however, are not satisfactory. Selection of the risk measure or the allocation rule is arbitrary, which may provoke dispute among interested parties. The allocated capital is not additive: the amount allocated to any part of the company is influenced by how this part and 
the rest of the company are subdivided. Also, these methods lack closed-form solutions, making further understanding of the results difficult.

Additive allocation methods do not calculate the standalone capital, but directly provide the amount allocated to each member. The first additive allocation method was developed by Myers and Read (2001). The authors analyze the default risk of the company and each of the members. They define the default ratio as the present value of default cost divided by the value of liability. For a given default ratio, a small change in the amount of exposure causes a small change in the required capital. A key observation in Myers and Read (2001) is that these "continuous" marginal capitals of the members add up to the total company capital. Since the cost of default can be viewed as an option - the default exchange option - the option pricing theory can be used to calculate the marginal capital. However, the method is not entirely convincing. Mildenhall (2004) points out the continuous marginal capital is not an appropriate notion in insurance since a line of business consists of discrete exposures. Sherris (2006) comments that the default ratio usually is not constant across lines. On the technical side, to get a closed-form solution using the option pricing approach, assets and liabilities need to be jointly lognormal. This is a restrictive assumption in insurance.

Recently Kreps (2005) and Ruhm, Mango \& Kreps (2006) propose a general framework for allocating capital and other risk charges. The result is formulated as a certain integral called the "co-measure". The integral form implies the allocation is additive. To a large extent the converse is also true: any additive allocation can be written in the co-measure form, see Ruhm, Mango \& Kreps (2006) and Venter (1991). A key step in the Ruhm-Mango-Kreps algorithm is to find a suitable kernel of integration, called the "riskiness leverage function" by Kreps (2005). The user has the freedom of selecting from infinitely many reasonable leverage functions. Kreps (2005) and Ruhm, Mango \& Kreps (2006) study examples of such functions that produce some popular risk measures on the company level.

In the banking industry similar capital allocation problems exist. Kalkbrener (2005) and Kalkbrener, Lotter and Overbeck (2004) apply an "axiomatic" approach to credit portfolios. Kalkbrener (2005) establishes the existance and uniqueness of capital allocation that satisfies a few basic mathematical principles. He also derives closed-form allocation formulas corresponding to some common risk measures.

We propose a new additive allocation method in this paper. The method is partially inspired by the Myers-Read approach, and is consistent with the RuhmMango-Kreps and the Kalkbrener algorithms. Sherris (2006) explains how the expected value of default should be distributed to policies based on the rule of asset payoff at the time of insolvency. From this basic result we derive a set of closed-form capital allocation formulas. They have straightforward economic meaning and are uniquely determined. Although the liabilities are the main risk source for an insurance firm, the investments, expenses, and other balance sheet items may also contribute significant amount of risk. Our method treats all these risks in a uniform framework, and allocates capital among all of them.

The paper is organized as follows. In Section 2 we review the allocation of the expected value of default stated in Sherris (2006). Our main results are presented 
in sections 3 and 4. The initial capital is first allocated between the total asset and the total liability, and then further split among individual assets and liabilities. A numerical example is given in Section 5 to demonstrate a step-by-step calculation. It is a simple process after a joint distribution of assets and liabilities is simulated. In Section 6 we discuss some additional qualities of the method.

\section{Allocation of Expected Value of Default}

An insurance company defaults when its total liability becomes greater than the total asset. The difference between the terminal values of liability and asset is called the value of default. What happens after a company defaults depends on the regulation. In an unregulated insurance market, the policyholders of the company bear the entire cost. They can not recover some of the losses. The total unrecoverable amount equals the value of default. To be fair to the policyholders, the expected value of default, discounted to the time of policy issuance, is deducted from the total company premium. This premium credit is then spread out to individual policies according to some economic principle.

In a regulated insurance market, guaranty funds are set up to pay the claims of insolvent insurance companies. Fund balances are accumulated by assessing all companies. In some juristictions, the assessment is collected periodically before any insolvencies; in others, it is done after an insolvency occurs. A policy issued by a company is thus guaranteed by the whole industry. If the guaranty fund system is perfect, the only possible default is that of the entire industry. Treating the industry as one giant insurer, we can estimate the expected value of default of the industry and allocate it among the policies of all companies. The allocated expected value of default must be much smaller than that in the unregulated case. In reality, however, the guaranty fund mechanism is far from perfect. The fund incurs its own expenses; policyholders wait longer to receive their payments, and sometimes do not get full recovery; and mismatch exists between the amount of assessment a company pays and the default cost it is expected to produce. In this paper, we do not consider these complicating issues, but limit the discussion to the unregulated situation.

Consider a one-period model, where all policies are written at time 0 and all claims paid at time 1 . Assume an insurance company writes $n$ policies. A policy loss payment at time 1 is a random variable $L_{i}$. The initial shareholder investments plus all policy premiums make up the company asset at time 0 . Assume the assets are invested in $m$ different funds with market values $a_{1}, \ldots, a_{m}$, and one-period random returns $R_{1}, \ldots, R_{m}$, respectively. So at time 1 the $j$ th fund has random value $A_{j} \equiv a_{j}\left(1+R_{j}\right)$. Finally, use $l_{i}$ to denote the fair value of liability $L_{i}$ at time 0 . According to the summary report by the Fair Value Task Force (2002), if a policy can be traded in an open market, the fair value equals the market value; otherwise, the fair value is calculated using the discounted cash flow (DCF) method, with an adjustment for risk. Technical details of fair valuation are still under development. The main results in this paper can be stated as an allocation of the insurer's asset, 
where the exact values of $l_{1}, \ldots, l_{n}$ are not used. Knowing the value of $l_{i}$, one can further split the amount of asset allocated to the $i$ th policy into $l_{i}$ and a corresponding allocated capital. We summarize the assets and liabilities as follows

$$
\begin{aligned}
& \text { total liability at time } 0 \text { (fair value) }: l=\sum_{i=1}^{n} l_{i}, \\
& \text { total liability at time } 1 \text { (random) }: L=\sum_{i=1}^{n} L_{i}, \\
& \text { total asset at time } 0 \text { (market value) }: a=\sum_{j=1}^{m} a_{j}, \\
& \text { total asset at time } 1 \text { (random) }: A=\sum_{j=1}^{m} A_{j} .
\end{aligned}
$$

Assume the company is solvent at time 0 . Then $k \equiv a-l>0$. This is the company capital at time $0 . k$ is called the economic capital, since the values of $a$ and $l$ are consistent with the market. The economic capital is more relevant in pricing and risk management than the statutory surplus or the US GAAP equity, which are subject to arbitrary accounting rules.

The company defaults at time 1 if $L>A$. The default value is $D \equiv L-A$. Let $\Omega \equiv\{\omega\}$ be the set of possible events at time 1. Define a subset $\Delta \equiv\{\omega \mid L(\omega)>A(\omega)\}$. $\Delta$ is called the default set. The expected value of default is

$$
d \equiv E\left[D 1_{\Delta}\right]=E\left[(L-A) 1_{\Delta}\right]
$$

where the function $1_{\Delta}$ equals 1 on $\Delta$ and 0 elsewhere. $d$ is also called the expected policyholder deficit in the actuarial literature. It is the expected unrecoverable loss for the entire policyholder body. In Myers \& Read (2001) and Sherris (2006), the riskadjusted present value of $d$ is viewed as the price of an insolvency exchange option.

When a company defaults, the entire asset is paid to the policyholders. The assets are conventionally distributed in proportion to a policyholder's outstanding claims. So the $i$ th policyholder is paid an amount of $\left(L_{i} / L\right) A$, and the remaining $\left(L_{i} / L\right)(L-A)$ is unrecoverable. Thus $E\left[\left(L_{i} / L\right)(L-A) 1_{\Delta}\right]$ is the expected unrecoverable loss for the policyholder, denoted by

$$
d_{i} \equiv E\left[\frac{L_{i}}{L}(L-A) 1_{\Delta}\right] .
$$

It is easy to see $d=\sum_{i=1}^{n} d_{i}$. This allocation of the expected value of default is first explicitly shown in Sherris (2006). It is also implicitly contained in Phillips, Cummins \& Allen (1998). Obviously, to be fair to the policyholders, the discounted value of $d_{i}$ should be subtracted from the premium of the $i$ th policy. This type of premium credit has been advocated in many papers, including Phillips, Cummins \& Allen (1998), Myers \& Read (2001) and Sherris (2006). Note that the discounting of $d_{i}$ is no trivial matter. It should include an adjustment for risk. Rigorous treatment requires modern finance. Sherris (2006) defines a risk-neutral probability $Q$ on the set $\Omega$. If expected values of cash flows are computed with respect to $Q$, then 
all discountings are done at the risk-free rate. Equivalently, Myers \& Read (2001) use a state-price density function to calculate present values. We take a more practical approach in this paper. The objective probability is used throughout.

\section{Allocating Capital to Assets}

We will allocate the initial capital $k$ to both liabilities and assets. The amount allocated to an asset reflects the asset's contribution to company total risk. If a company decides to invest in high risk securities for potentially more profit, its total risk usually increases. Thus the required capital increases. Intuitively, the extra capital should mostly be allocated to the risky assets, rather than to liabilities. On the other hand, if the total amount of capital is fixed, swapping high risk investments for low risk ones alters the distribution of capital. Some capital amount is moved from supporting liabilities to supporting assets. Later in Section 6, we extend our allocation scheme to other risky items on the balance sheet. All risky items are allocated a portion of $k$ according to its contribution to the company default risk.

Split the total capital into two parts, $k=k^{l}+k^{a} . k^{l}$ and $k^{a}$, to be determined, are the capital amounts allocated to the total liability and the total asset, respectively. Let $r$ be the risk free rate. We rewrite the value of default as

$$
\begin{aligned}
D & =L-A=L-(l+k)(1+r)+a(1+r)-A \\
& =\left[L-\left(l+k^{l}\right)(1+r)\right]+\left[\left(a-k^{a}\right)(1+r)-A\right] .
\end{aligned}
$$

Imagine a hypothetical company that carries a total liability $L$, holds an initial capital $k^{l}$, and invests its total asset $l+k^{l}$ risk-free. Then the value of default is $L-\left(l+k^{l}\right)(1+r)$, whenever $L>\left(l+k^{l}\right)(1+r)$. For our actual company, we may think of the same quantity $L-\left(l+k^{l}\right)(1+r)$ as the value of default attributed to the liabilities, defined on the default set $\Delta$. A parallel argument may be applied to assets. Let a hypothetical company carry a risky asset $A$, an initial capital $k^{a}$, and a non-random liability. The non-random liability is actually a debt, whose initial value is $a-k^{a}$ and time- 1 value is $\left(a-k^{a}\right)(1+r)$. Then the company defaults if $A<\left(a-k^{a}\right)(1+r)$ and the default value is $\left(a-k^{a}\right)(1+r)-A$. So $\left(a-k^{a}\right)(1+r)-A$, on the set $\Delta$, can be regarded as the value of default attributed to the assets. From (3.1) and (2.1) we have

$$
E\left[\left(L-\left(l+k^{l}\right)(1+r)\right) 1_{\Delta}\right]+E\left[\left(\left(a-k^{a}\right)(1+r)-A\right) 1_{\Delta}\right]=d,
$$

where the first term is the expected value of default attributed to the liabilities, and the second term attributed to the assets. We now seek to split $d$ into a liability portion and an asset portion. The discussion in Section 2 suggests that the entire amount $d$ be allocated among the liabilities, so that the present value of $d$ could be deducted from the premiums. Thus a zero amount of the expected default is attributed to the assets. That is, 


$$
\begin{aligned}
& E\left[\left(L-\left(l+k^{l}\right)(1+r)\right) 1_{\Delta}\right]=d, \\
& E\left[\left(\left(a-k^{a}\right)(1+r)-A\right) 1_{\Delta}\right]=0 .
\end{aligned}
$$

Solving for $k^{l}$ and $k^{a}$ we have

$$
\begin{aligned}
& k^{l}=\frac{1}{\operatorname{Prob}(\Delta)}\left(E\left[\left(\frac{L}{1+r}-l\right) 1_{\Delta}\right]-d\right), \\
& k^{a}=\frac{1}{\operatorname{Prob}(\Delta)} E\left[\left(a-\frac{A}{1+r}\right) 1_{\Delta}\right] .
\end{aligned}
$$

These two formulas distribute the capital between the total liability and the total asset. (Obviously, $k^{l}+k^{a}=k$ ). In equation (3.5), substituting (2.1) for $d$ we get

$$
k^{l}=\frac{1}{\operatorname{Prob}(\Delta)} E\left[\frac{A}{1+r} 1_{\Delta}\right]-l,
$$

or,

$$
l+k^{l}=\frac{1}{\operatorname{Prob}(\Delta)} E\left[\frac{A}{1+r} 1_{\Delta}\right]
$$

In (3.8), $l+k^{l}$ may be regarded as the amount of initial asset allocated to the liability. Thus, equations (3.6) and (3.8) provide an allocation of the asset $a$ : $k^{a}$ to support the risky investments and $l+k^{l}=a-k^{a}$ to support the liabilities. Note that $l$ does not appear on the right-hand side of (3.8). So the valuation of liabilities is nonessential. Further splitting of $k^{l}$, or $l+k^{l}$, will be discussed in the next section.

Equation (3.6) has a straightforward economic interpretation. The default set $\Delta$ is a set of extreme events, and is a small set for financially healthy firms. The value of $A$ on the set $\Delta$ is a kind of "tail value". The value of $a-A /(1+r)$, if positive, measures the downside swing of the random asset $A$. So (3.6) calculates the average downside swing of the asset value on $\Delta$. The larger the downside swing, the greater risk the asset contributes, thus the greater amount of allocated capital $k^{a}$. (3.6) may also be written as

$$
k^{a}=a-\frac{1}{\operatorname{Prob}(\Delta)} E\left[\frac{A}{1+r} 1_{\Delta}\right] .
$$

$k^{a}$ can be further split into $k_{1}^{a}, \ldots, k_{m}^{a}$, corresponding to the $m$ different investments, so that

$$
E\left[\left(\left(a_{j}-k_{j}^{a}\right)(1+r)-A_{j}\right) 1_{\Delta}\right]=0
$$

This equation is parallel to (3.4). It means that a zero amount of expected default is attributed to each of the investments. Solving for $k_{j}^{a}$, yields 


$$
\begin{aligned}
k_{j}^{a} & =\frac{1}{\operatorname{Prob}(\Delta)} E\left[\left(a_{j}-\frac{A_{j}}{1+r}\right) 1_{\Delta}\right] \\
& =a_{j}-\frac{1}{\operatorname{Prob}(\Delta)} E\left[\frac{A_{j}}{1+r} 1_{\Delta}\right] .
\end{aligned}
$$

This is the capital amount allocated to the $j$ th asset.

The asset capital can be thought of as a deduction to the value of a risky investment. The $j$ th investment has a market value of $a_{j}$. But its risk contributes to the company default, so it has a lower value to the company. We may say it has a "default-free equivalent value" of $a_{j}-k_{j}^{a}$. In particular, if the $j$ th asset is risk free, then $A_{j}=(1+r) a_{j}$. (3.11) implies $k_{j}^{a}=0$, that is, no capital is allocated to a riskfree asset, as expected. The asset capital is not used in ratemaking, but it may provide a guidance to the selection of investments. Other things being equal, an investment with less $k_{j}^{a}$ is more attractive.

\section{Allocation of the Liability Capital}

Split $k^{l}$ into $n$ terms $k^{l}=k_{1}^{l}+\cdots+k_{n}^{l}$, and write (3.3) as

$$
\sum_{i=1}^{n} E\left[\left(L_{i}-\left(l_{i}+k_{i}^{l}\right)(1+r)\right) 1_{\Delta}\right]=d .
$$

Imagine that a stand alone company writes only one policy with loss $L_{i}$, carries a capital amount $k_{i}^{l}$, and invests the asset $l_{i}+k_{i}^{l}$ at the risk-free rate, then the value of default is $L_{i}-\left(l_{i}+k_{i}^{l}\right)(1+r)$, whenever $L_{i}>\left(l_{i}+k_{i}^{l}\right)(1+r)$. In our multi-policy company, consider the same quantity $L_{i}-\left(l_{i}+k_{i}^{l}\right)(1+r)$ as the value of default contributed by the $i$ th policy, on the default set $\Delta$. So each term on the left-hand side of (4.1) is the expected default value attributed to the $i$ th policy. It should equal the economic default value $d_{i}$ given by equation (2.2),

$$
E\left[\left(L_{i}-\left(l_{i}+k_{i}^{l}\right)(1+r)\right) 1_{\Delta}\right]=d_{i} .
$$

Substitute (2.2) for $d_{i}$ and solve,

$$
k_{i}^{l}=\frac{1}{\operatorname{Prob}(\Delta)} E\left[\frac{L_{i}}{L} \frac{A}{1+r} 1_{\Delta}\right]-l_{i}
$$

or,

$$
l_{i}+k_{i}^{l}=\frac{1}{\operatorname{Prob}(\Delta)} E\left[\frac{L_{i}}{L} \frac{A}{1+r} 1_{\Delta}\right]
$$

$k_{i}^{l}$ is the amount of capital allocated to the $i$ th policy, and $l_{i}+k_{i}^{l}$ the amount of allocated asset. The right-hand side of (4.4) does not depend on the value of $l_{i}$. 
In actual calculation the allocated assets are obtained first. If $l_{i}$ is known, then it can be subtracted out from the allocated asset to get the allocated capital. From (4.4), the amount of allocated asset is determined by the values of $L_{i}, L$ and $A$ on the set $\Delta$, the "tail values" of these variables. Other things being equal, the larger the average value of $L_{i}$ on the set $\Delta$, the greater risk the policy contributes, thus the greater the allocated asset.

We have stated the allocation of expected default (2.2) and that of the liability capital (4.3) for individual policies. Obviously these formulas also hold for any groups of policies, such as lines of business or underwriting units. The allocation is additive: the amount of capital allocated to a group of policies equals the sum of those allocated to the individual policies.

It is interesting to look at some special cases. Assume a liability $L_{i}$ is nonrandom, then $l_{i}=L_{i} /(1+r)$. When the company becomes insolvent, according to the payoff rule stated in Section 2, this policy also suffers from unrecoverable loss. Equation (4.3) implies $k_{i}^{l}=l_{i} \cdot\left(1 / \operatorname{Prob}(\Delta) \cdot E\left[A / L \cdot 1_{\Delta}\right]-1\right)$. Since $A<L$ on the set $\Delta$, we have $k_{i}^{l}<0$. The negative sign means such a policy helps reduce the total required capital. In the words of Venter (2003), the policy is a "supplier of capital, not a user". A more extreme case is when $L_{i}=0$ on $\Delta$. The allocated capital achieves its minimum value: $k_{i}^{l}=-l_{i}$. This policy has a maximum diversification effect in the company. It is similar to a perfectly negatively correlated asset in an investment portfolio. Other additive allocation methods, including Myers \& Read (2001), Kreps (2005), Ruhm, Mango \& Kreps (2006) and Kalkbrener (2005), also produce negative capitals for policies with strong negative correlations. Venter (2003) analyzes such an example for the Myers-Read approach.

\section{A Numerical EXAMPLE}

In practice, once the joint probability distribution of investments and policy losses is simulated, the allocated capitals are easy to compute. As an example, we examine a company that writes three policies and invests its initial asset in two funds. Assume there are 10 possible events at time 1 with equal probability. Table 1 shows the values of the two investments and the three policy losses at each event. The 1st policy incurs great losses with a small probability. It resembles a catastrophe coverage. It has the greatest coefficient of variation (CV). Assume the risk free rate is $3 \%$. The 2 nd investment is a risk free bankaccount with 1,000 initial value. The initial value of the 1 st investment is less than the risk-free discounted expected value of $A_{1}$, so that the expected return of the asset, $\left(E\left[A_{1}\right]-a_{1}\right) / a_{1}$, is greater than $3 \%$. Similarly, each $l_{i}$ is greater than the corresponding risk-free discounted value $E\left[L_{i}\right] / 1.03$, the difference representing a risk load. The catastrophe policy has the greatest risk load relative to its mean loss.

The time 1 values in Table 1 is sorted by $A-L$ in decending order. The default set $\Delta$ thus contains two events, the 9 th and the 10th. The probability of insolvency $\operatorname{Prob}(\Delta)=0.2$. Table 2 demonstrates the calculations using formulas (3.11) and (4.4). As expected, the risk free investment requires zero amount of capital. Among the 
TABLE 1

VALUES OF AsSETS AND LiabiLITIES

\begin{tabular}{|c|c|c|c|c|c|c|c|c|}
\hline \multicolumn{9}{|c|}{ PRESENT VAlues at TIME 0} \\
\hline & $a_{1}$ & $a_{2}$ & $l_{1}$ & $l_{2}$ & $l_{3}$ & $a$ & $l$ & $k$ \\
\hline & 2,040 & 1,000 & 330 & 460 & 1,620 & 3,040 & 2,410 & 630 \\
\hline \multicolumn{9}{|c|}{ RANDOM VALUES AT TIME 1} \\
\hline Event & $A_{1}$ & $A_{2}$ & $L_{1}$ & $L_{2}$ & $L_{3}$ & $A$ & $L$ & $A-L$ \\
\hline 1 & 2,860 & 1,030 & 0 & 750 & 60 & 3,890 & 810 & 3,080 \\
\hline 2 & 3,300 & 1,030 & 0 & 900 & 1,150 & 4,330 & 2,050 & 2,280 \\
\hline 3 & 2,150 & 1,030 & 0 & 480 & 500 & 3,180 & 980 & 2,200 \\
\hline 4 & 1,500 & 1,030 & 0 & 430 & 850 & 2,530 & 1,280 & 1,250 \\
\hline 5 & 2,300 & 1,030 & 800 & 540 & 1,400 & 3,330 & 2,740 & 590 \\
\hline 6 & 2,040 & 1,030 & 0 & 190 & 2,450 & 3,070 & 2,640 & 430 \\
\hline 7 & 1,020 & 1,030 & 0 & 50 & 1,700 & 2,050 & 1,750 & 300 \\
\hline 8 & 2,510 & 1,030 & 0 & 630 & 2,900 & 3,540 & 3,530 & 10 \\
\hline 9 & 1,800 & 1,030 & 0 & 300 & 3,500 & 2,830 & 3,800 & -970 \\
\hline 10 & 1,960 & 1,030 & 2,200 & 370 & 2,050 & 2,990 & 4,620 & $-1,630$ \\
\hline Mean & 2,144 & 1,030 & 300 & 464 & 1,656 & 3,174 & 2,420 & 754 \\
\hline SD & 654 & 0 & 713 & 256 & 1,085 & 654 & 1,277 & 1,477 \\
\hline $\mathrm{CV}$ & 0.30 & 0 & 2.38 & 0.55 & 0.66 & 0.21 & 0.53 & 1.96 \\
\hline
\end{tabular}

TABLE 2

Calculation of Allocated Capitals

\begin{tabular}{|c|c|c|c|c|c|c|}
\hline $\begin{array}{l}r \\
\operatorname{Prob}(\Delta)\end{array}$ & $\begin{array}{c}3 \% \\
0.20\end{array}$ & & & & & \\
\hline & $A_{1}$ & $A_{2}$ & $L_{1}$ & $L_{2}$ & $L_{3}$ & Total \\
\hline$E\left[A_{j} \cdot 1_{\Delta}\right]$ & 376 & 206 & & & & \\
\hline$k_{j}^{a}$ & 215 & 0 & & & & 215 \\
\hline$E\left[L_{i} / L \cdot A \cdot 1_{\Delta}\right]$ & & & 142 & 46 & 393 & \\
\hline$l_{i}+k_{i}^{l}$ & & & 691 & 225 & 1,909 & 2,825 \\
\hline$k_{i}^{l}$ & & & 361 & -235 & 289 & 415 \\
\hline$k_{i}^{l} / l_{i}$ & & & 1.09 & -0.51 & 0.18 & 0.17 \\
\hline
\end{tabular}

three policies, the $1 \mathrm{st}$ is the most risky, so the amount of capital per unit of loss, $k_{i}^{l} / l_{1}=1.09$, is the largest.

The three policies have the following correlation coefficients: $\rho\left(L_{1}, L_{2}\right)=-0.09$, $\rho\left(L_{2}, L_{3}\right)=-0.42$, and $\rho\left(L_{3}, L_{1}\right)=0.1$. Note that $L_{2}$ is negatively correlated with 
the rest of the liabilities. It is not surprising the policy is allocated a negative amount of capital. Polices like this provide extraordinary diversification benefits.

\section{Discussions And Conclusions}

Our allocation results are given in closed-form formulas. Practical implementation is straightforward once the random assets and liabilities are simulated. The formulas also provide some useful qualitative information. The allocated capitals $k_{j}^{a}$ and $k_{i}^{l}$ are continuous functions of the amount of insured exposure. When a small policy is added to the existing book of business, a small amount of premium is collected and invested. Both $L$ and $A$ are increased by a small amount. (The meaning of smallness can be made rigorous mathematically.) So the set $\Delta$ is changed slightly. Using equations (3.11) and (4.3) we see $k_{j}^{a}$ and $k_{i}^{l}$ only change by a small amount. The continuity is a natural requirement of an allocation method.

Unlike most previous work, our method treats both invested assets and liabilities in a uniform framework. We can further extend the method to allocate capital among all risky items on the balance sheet. For instance, operational risks have the potential to generate great expenses. Suppose such an expense can be modeled with a random variable $F$. Using the DCF approach we also estimate its risk adjusted present value to be $f$. Modify the definition of the default set as $\Delta \equiv\{\omega \mid$ $L(\omega)+F(\omega)>A(\omega)\}$. The total capital at time 0 is $k=a-l-f$. The amount allocated to the expense is given by

$$
\begin{aligned}
k^{f} & =\frac{1}{\operatorname{Prob}(\Delta)} E\left[\left(\frac{F}{1+r}-f\right) 1_{\Delta}\right] \\
& =\frac{1}{\operatorname{Prob}(\Delta)} E\left[\frac{F}{1+r} 1_{\Delta}\right]-f .
\end{aligned}
$$

Equation (6.1) is identical to (3.11) except for a negative sign. $k^{f}$ measures the risk the expense item contributes. $k^{f}$ is large if $F$ exceeds $(1+r) f$ by a large amount on the default set $\Delta$. In general, (6.1) is used to allocate capital to any risky items on the liability side of the balance sheet. On the asset side, many kinds of noninvestable assets are also exposed to considerable risk, one notable example being the reinsurance recoverables from a low quality reinsurer. These assets are treated the same way as the invested assets. Their allocated capitals are computed using equation (3.11).

The allocation formulas (3.11), (4.3) and (4.4) are in the "co-measure" form, so are consistent with the Ruhm-Mango-Kreps algorithm (Kreps (2005) and Ruhm, Mango \& Kreps (2006)). Usually the first step of using the Ruhm-Mango-Kreps algorithm is to pick a riskiness leverage function, a somewhat arbitrary decision. In contrast, our solution is derived from the allocation of the expected default (2.2), which is based on the claim payoff rule as a company becomes insolvent. So it is grounded directly on economics, and is uniquely determined. Kalkbrener (2005) studies the capital allocation problem for credit portfolios. He proposes a set of 
axioms that can uniquely determine the allocation for a given risk measure, and finds closed-form allocation formulas corresponding to some common risk measures. In Kalkbrener (2005) and Kalkbrener, Lotter \& Overbeck (2004), the expected shortfall, similar to our expected value of default, is selected as a preferred risk measure. The resulting allocated capital, restated in our notation, is $1 / \operatorname{Prob}(\Delta) \cdot$ $E\left[L_{i} \cdot 1_{\Delta}\right]-l_{i}$, the same as (3.11) or (6.1). But equation (4.3) for allocating the liability capital is not associated with any popular risk measures.

\section{ACKNOWLEGEMENTS}

I thank David Ruhm for reading an earlier draft of the paper and providing many comments. Discussions with Steve Mildenhall helped me understand recent researches on the subject. I also thank the ASTIN Bulletin reviewers for comments and suggestions.

\section{REFERENCES}

FAIr VAlue TASK ForCe (2002) Fair Value of Insurance Liabilities: Principles and Methods, American Academy of Actuaries, Washington, DC. Online at \{http://www.actuary.org/pdf/finreport/ fairval_sept02.pdf

Kalkbrener, M. (2005) An Axiomatic Approach to Capital Allocation. Mathematical Finance 15(3), 425-437.

Kalkbrener, M., Lotter, H. and Overbeck, L. (2004) Sensible and Efficient Capital Allocation for Credit Portfolios. Risk 2005 (January), S19-S24.

Kreps, R. (2005) Riskiness Leverage Models. Proceedings of the Casualty Actuarial Society XCII, 31-60.

Mildenhall, S. (2004) A Note on the Myers and Read Capital Allocation Formula. North American Actuarial Journal 8 (April).

Myers, S. and READ, J. (2001) Capital Allocation for Insurance Companies. Journal of Risk and Insurance 68(4), 545-580.

Phillips, R., Cummins, J.D. and Allen, F. (1998) Financial Pricing of Insurance in the Multi-Line Insurance Company. Journal of Risk and Insurance 65(4), 597-636.

Ruhm, D., Mango, D. and Kreps, R. (2006) A General Additive Method for Portfolio Risk Analysis. ASTIN Bulletin, to appear.

SHERris, M. (2006) Solvency, Capital Allocation and Fair Rate of Return in Insurance. Journal of Risk and Insurance 73(1), 71-96.

Venter, G. (1991) Premium Calculation Implications of Reinsurance Without Arbitrage. ASTIN Bulletin 21(2), 223-230.

Venter, G. (2003) Capital Allocation: An Opinionated Survey. Casualty Actuarial Society Forum 2003 (summer), 279-305.

YINGJIE ZHANG

CNA Insurance Companies, 333 S. Wabash Ave. 30S,

Chicago, IL 60604, USA

Tel: +1-312-822-4372

E-mail: yingjie.zhang@cna.com 